\title{
Interaction of arsenic trioxide and etoposide in Ewing sarcoma cell lines
}

\author{
JULIA E. LENZ ${ }^{1,2}$, ROSA RIESTER ${ }^{2}$, SABINE B. SCHLEICHER $^{3}$, \\ RUPERT HANDGRETINGER ${ }^{3}$, KAREN A. BOEHME ${ }^{2}$ and FRANK TRAUB ${ }^{1,2}$ \\ ${ }^{1}$ Department of Orthopaedic Surgery, Eberhard Karls University Tuebingen, \\ D-72076 Tuebingen; ${ }^{2}$ Department of Orthopaedic Surgery, Laboratory of Cell Biology, \\ Eberhard Karls University Tuebingen, D-72072 Tuebingen; ${ }^{3}$ Department of Hematology and Oncology, \\ Children's Hospital, Eberhard Karls University Tuebingen, D-72076 Tuebingen, Germany
}

Received May 7, 2019; Accepted September 25, 2019

DOI: $10.3892 /$ or.2019.7409

\begin{abstract}
Ewing sarcomas (ES) are highly malignant mesenchymal tumors, which most often occur in children and adolescents. The current treatment of choice comprises wide resection in combination with multimodal chemotherapy including etoposide (Eto). Due to the serious side effects associated with common chemotherapeutics and prevalent multidrug resistance in recurrent and metastatic ES, there is a growing demand for alternative strategies and add-on drugs. Previous research has demonstrated efficient cell death induction by Eto in combination with arsenic trioxide (ATO) in ES cell lines. The aim of the present study was to investigate the effect of different temporal sequences of ATO and Eto administration on apoptosis induction and to explore the effect of both drugs on inhibitory glycogen synthase kinase-3 $\beta$ (GSK3- $\beta$ ) phosphorylation as well as multidrug transporter gene expression. The intensity of caspase activation was mainly determined by the Eto doses in A673 and TC-71 cells, whereas in RD-ES cells ATO application actively suppressed Eto-induced apoptosis. This coincided with an increase in inhibitory GSK-3 $\beta$ phosphorylation in ATO-treated RD-ES cells. Inherent mRNA expression of multidrug resistance-associated protein 1 (MRP1)
\end{abstract}

Correspondence to: Dr Karen A. Boehme, Department of Orthopaedic Surgery, Laboratory of Cell Biology, Eberhard Karls University Tuebingen, Waldhoernlestrasse 22, D-72072 Tuebingen, Germany

E-mail: karen.boehme@web.de

Abbreviations: ATO, arsenic trioxide; ES, Ewing sarcoma(s); EWS, Ewing sarcoma breakpoint region; Eto, etoposide; FLI1, Friend leukemia integration 1; GLI1, glioma associated oncogene family 1; GSK3- $\beta$, glycogen synthase kinase-3 $\beta$; MDR1, multidrug resistance protein 1; MRP1, multidrug resistance-associated protein 1; MSC, mesenchymal stem cells

Key words: Ewing sarcoma, etoposide, arsenic trioxide, apoptosis, multidrug resistance, glycogen synthase kinase-3, glioma associated oncogene family 1 was low in the ES cell lines compared to that observed in the mesenchymal stem cells (MSC), whereas multidrug resistance protein 1 (MDR1) gene expression was considerably increased in the ES cell lines. ATO treatment reduced MRP1 mRNA expression in the A673 and TC-71 cells, while expression was induced in the MSC and RD-ES cells. In contrast, MDR1 mRNA expression was specifically induced by ATO in the A673 and TC-71 cells, reinforcing the expression differences between MSC and the ES cell lines. Although a reliable cell death induction by the combination of ATO and Eto has been previously shown in ES cell lines, the present study showed marked heterogeneity of the ES cell response to ATO and Eto treatment, illustrating the difficulty of prediction of individual treatment outcome in ES.

\section{Introduction}

Ewing sarcomas (ES) are aggressive mesenchymal tumors, which most often occur in children, adolescents and young adults. They are the second most prevalent malignant bone tumors (1). The exact genesis of ES is still unclear. Currently, mesenchymal stem cells (MSC) are considered as the most probable cells of origin (2). Various gene translocations, which define the disease, are discussed as a trigger for ES formation. The most common rearrangement is the reciprocal $\mathrm{t}(11 ; 22)(\mathrm{q} 24$; q12) translocation, which occurs in approximately $85 \%$ of all cases and fuses the Ewing sarcoma breakpoint region (EWS) 1 gene with the Friend leukemia integration (FLI) 1 gene (1).

The EWS-FLI1 oncoprotein acts as a transcription factor and promotes, among others, the expression of glioma associated oncogene family 1 (GLI1) (3) and insulin-like growth factor 1 (IGF1) mRNA, while numerous additional targets are repressed by EWS-FLI1 (1). Hence, overexpression of GLI1 protein triggered by EWS-FLI1 may be assumed, although this has not been confirmed for the ES cell lines A673, RD-ES and SK-N-MC, which all express the EWS-FLI1 fusion protein (4), while GLI1 protein expression is commonly reduced compared to that in MSC (5). GLI1 expression in the ES cell line TC-71 has been previously shown at the mRNA and protein levels (3). In TC-71 cells, arsenic trioxide (ATO) was found to have no effect on GLI1 protein expression but inhibited the 
transcriptional activity of GLI1 proven by reduced expression of target genes (6). The authors attributed the ATO-dependent apoptosis induction in ES cell lines (determined by TUNEL assay) at least partially to GLI1 inhibition (6).

Fusion protein-positive ES form genomic stable tumors with a few additional somatic mutations mostly affecting p16 and p53 function. Yet, EWS-FLI1 expression is heterogeneous leading phenotypic plasticity and chemotherapy increases mutation numbers, which has been linked to poor outcome $(4,7,8)$. Acquired multidrug resistance is a common feature of ES, which have been shown to express both multidrug resistance-associated protein 1 (MRP1) and multidrug resistance protein 1 (MDR1), also known as P-glycoprotein 1 (PGP1) (9-11). Both, the SK-N-MC and TC-71 (also EWS-FLI1-positive) cell lines were established after chemotherapy from a metastatic site (SK-N-MC) or local recurrence (TC-71) (8). In contrast, RD-ES cells originate from a primary tumor (12). The A673 cell line has been established without further documentation of the site of origin. Neither for RD-ES nor for A673 is a treatment history available.

For ES, the actual ESMO-PaedCan-EURACAN guideline recommends multimodal chemotherapy including doxorubicin, cyclophosphamide, ifosfamide, vincristine, dactinomycin and etoposide (Eto) combined with radiation therapy (13). Eto acts as a topoisomerase-2-inhibitor and clinically achievable doses in the plasma of ES patients are approximately $10 \mu \mathrm{g} / \mathrm{ml}(8)$. Patients suffering from recurrent or metastatic ES have a poor prognosis. Previously achieved cumulative doses of chemotherapeutic agents afford the individualization of second line treatments which may also contain Eto (13). Topoisomerase-2 inhibition by Eto causes DNA damage, cell cycle arrest and apoptosis via p53-dependent and -independent pathways (14). Activation of the intrinsic mitochondrial apoptosis pathway by Eto has been shown to be dependent on active glycogen synthase kinase-3 (GSK-3) (15-17).

ATO has been established for the treatment of acute promyelocytic leukemia (APL) (18). Moreover, it has been shown to induce cell death of different solid tumor cells in vitro at concentrations of 0.1-5 $\mu \mathrm{M}$, which can also be obtained in the plasma of patients $(5,19-21)$. ATO has the property of binding and inhibiting the GLI1 protein directly (22) but also targets many additional pathways implicated in proliferation, metabolism and cell death (23). Apoptosis induction by ATO is based on several interconnected mechanisms: First, inhibition of mitogenic signaling pathways including the Hedgehog ( $\mathrm{Hh})$ and Akt pathways $(22,24,25)$; second, enhanced production of reactive oxygen species (ROS) $(26,27)$; third, induction of endoplasmic reticulum stress and suppression of proteasome activity $(24,27)$; fourth, mitochondrial disruption and subsequent activation of the intrinsic apoptotic pathway (26-28), which may be facilitated by suppression of Bcl-2 expression (26), fifth, stabilization of securin and cyclin B directly inhibiting mitotic progression, which leads to centrosome fragmentation dependent apoptosis preferentially affecting rapidly growing cancer cells compared to differentiated resting cells (29). In human epidermoid carcinoma cells high doses of ATO $(20 \mu \mathrm{M})$ have been shown to induce ERK phosphorylation dependent GSK-3 inhibition leading to increased p21 expression as well as apoptosis (30). In human rhabdomyosarcoma cell lines $1 \mu \mathrm{M}$ ATO had a minor effect on GSK-3 $\beta$ serine 9 phosphorylation. Yet, it significantly increased lithium chloride-induced GSK-3 $\beta$ inhibition and apoptosis (31).

GSK-3 $\beta$ has been shown to act either in a pro-apoptotic or anti-apoptotic manner dependent on the pathway. The mitochondrial intrinsic apoptotic pathway is activated by GSK-3 $\beta$, whereas the death receptor-mediated extrinsic apoptotic signaling pathway is suppressed (32). Since both Eto and ATO are capable of activating the intrinsic mitochondrial apoptosis pathway $(15,27)$, it can be assumed that active GSK-3 $\beta$ is required for apoptosis induction by both drugs.

The combined application of ATO and Eto on ES cell lines has been shown to effectively reduce proliferation and viability concomitant with cell death induction (5). The present study investigated the effect of different chronological orders of low dose ATO and Eto administration on apoptosis induction in ES cell lines and explored the effect of both drugs on inhibitory GSK-3 $\beta$ phosphorylation as well as the ATO impact on multidrug transporter gene MRP1 and MDR1 expression.

\section{Materials and methods}

Reagents. ATO (Trisenox, Pharmacy of the University Hospital Tuebingen, Germany) was dissolved in purified water, and Eto (Selleckchem, Munich, Germany) was dissolved in dimethyl sulfoxide. For cell culture treatment stock solutions were further diluted in culture medium.

Cell lines and culture. RD-ES and A673 cells were obtained from CLS Cell Lines Service GmbH (Eppelheim, Germany). SK-N-MC (ATCC HTB-10) were purchased from the American Type Culture Collection (ATCC, Manassas, VA, USA). TC-71 cells were purchased from DSMZ (Braunschweig, Germany). RD-ES and SK-N-MC cells were maintained in RPMI-1640 medium with L-glutamine (Gibco, Life Technologies; Thermo Fisher Scientific, Inc.) supplemented with $15 \%$ fetal calf serum (FCS) (Biochrom, Berlin, Germany). A673 cells were cultivated in Dulbecco's modified Eagle's medium (DMEM) with GlutaMAX, $4.5 \mathrm{~g} / 1$ D-glucose (Gibco, Life Technologies; Thermo Fisher Scientific, Inc.) supplemented with $10 \%$ FCS. TC-71 cells were maintained in Iscove's modified Dulbecco's medium (IMDM), supplemented with $10 \%$ FCS.

Bone marrow-derived MSC were isolated at the University Hospital Tuebingen after written informed consent of the patients (approved by the ethics committee of the medical faculty, project no. 401/2013 BO2), propagated as previously described (33) and confirmed to represent multi-lineage differentiation potential toward chondrocytes, adipocytes and osteocytes (data not shown).

All cell lines were purchased from ATCC, CLS or DSMZ. Cryo-stocks were made and low passage cultures were used from these stocks. Cell line authentication was not performed as these cells derived from established cell banks and were submitted to in-house quality controls.

All cells were cultivated at $37^{\circ} \mathrm{C}$ in a humidified atmosphere containing $5 \% \mathrm{CO}_{2}$ and were regularly tested for absence of mycoplasma contamination by PCR (AppliChem, Darmstadt, Germany). 
$R N A$ isolation and RT-qPCR. RNA was isolated using the innuPREP RNA Mini Kit (Analytik Jena AG, Jena, Germany). One $\mu \mathrm{g}$ of RNA was reversely transcribed using the innuSCRIPT reverse transcriptase (Analytik Jena AG). cDNA (50 ng) was analyzed in duplicate reactions by quantitative RT-PCR (qRT-PCR) using gene-specific primers and the SYBR Select Master Mix for CFX (Thermo Fisher Scientific, Inc.) in a total volume of $10 \mu \mathrm{l}$. QRT-PCR was carried out in a CFX96 Real-Time PCR instrument (Bio-Rad Laboratories, Inc., Munich, Germany) and was analyzed using the CFX Manager ${ }^{\mathrm{TM}}$ software (Bio-Rad Laboratories, Inc.). Relative expression levels were calculated as fold change compared to MSC or basal expression using the $\Delta \Delta \mathrm{Ct}\left(2^{-\Delta \Delta \mathrm{Ct}}\right)$ method with TATA box binding protein (TBP) as a reference gene (34). The qRT-PCR primers were used as previously published: GLI1 (35), MDR1 (36), MRP1 (37) and TBP (38).

Cytotoxicity assay. Cell Titer $96^{\circledR}$ AQueous One Solution Cell Proliferation assay (Promega, Mannheim, Germany) (MTS) was used to measure cell viability via redox enzyme activity, according to the protocol provided by the manufacturer. TC-71 $\left(0.3 \times 10^{4}\right.$ cells/well $)$ or RD-ES $\left(0.5 \times 10^{4}\right.$ cells/well, Fig. S1) cells were grown in transparent F-bottom 96 -well plates. Twenty-four hours after seeding, the cells were incubated in the presence of ATO or Eto as indicated for another $96 \mathrm{~h}$ at $37^{\circ} \mathrm{C}$ in a humidified atmosphere of $5 \% \mathrm{CO}_{2}$ in air. At the end of the incubation period, MTS reagent was added to the wells, and the plate was incubated for $1.5 \mathrm{~h}$ protected from light. Absorbance was recorded at $490 \mathrm{~nm}$ with a reference wavelength of $630 \mathrm{~nm}$ using an EL 800 reader (BioTek, Winooski, VT, USA).

$I C_{50}$ determination. The half maximal inhibitory concentration $\left(\mathrm{IC}_{50}\right)$ values of ATO and Eto were determined for TC-71 cells by nonlinear regression using GraphPad Prism V8.0 software (GraphPad Software, Inc., La Jolla, CA, USA).

Caspase assay. Apo-ONE ${ }^{\circledR}$ Homogeneous Caspase-3/7 Assay (Promega) was used according to the protocol provided by the manufacturer. A673 $\left(0.5 \times 10^{4}\right.$ cells/well $)$, RD-ES $\left(0.25 \times 10^{4}\right.$ cells/well $)$, TC-71 $\left(0.15 \times 10^{4}\right.$ cells/well $)$ and MSC $\left(0.5 \times 10^{4}\right.$ cells/well $)$ were grown in black 96 -well plates with opaque F-bottom. Twenty-four hours after seeding, the cells were incubated in the presence of ATO, Eto or combinations as indicated for another $96 \mathrm{~h}$ at $37^{\circ} \mathrm{C}$ in a humidified atmosphere of $5 \% \mathrm{CO}_{2}$ in air. Excess primary drug-solution was removed prior to secondary drug application. At the end of the incubation period, the Z-DEVD-R110 substrate was added to the wells, and the plate was incubated for $1 \mathrm{~h}$ protected from light. Fluorescence was recorded at an excitation wavelength of $485 \mathrm{~nm}$ and emission wavelength of $528 \mathrm{~nm}$ with a Wallac 1420 Victor2 multilabel counter (Perkin Elmer, Waltham, MA, USA).

Western blot analysis. A673, RD-ES, SK-N-MC, TC-71 cells or MSC $\left(2.5 \times 10^{5}\right.$ cells/well) were incubated in 12-well plates for $48 \mathrm{~h}$. For analysis, the cells were washed with PBS and lysed in protein lysis buffer $(40 \mathrm{mM}$ Tris/ $\mathrm{HCl} \mathrm{pH} 7.4,300 \mathrm{mM}$ $\mathrm{NaCl}, 2$ mM EDTA, 20\% glycerol, 2\% Triton X-100) supplemented with proteinase inhibitor at $4^{\circ} \mathrm{C}$. Insoluble material was removed by centrifugation. The protein concentration in the supernatant was determined by Bradford protein assay. An amount $40 \mu \mathrm{g}$ of the protein samples was separated by $10 \%$ SDS-PAGE and transferred to a hydrophobic polyvinylidene difluoride (PVDF) membrane (Immobilon-P; Merck KGaA, Darmstadt, Germany). After blocking with $5 \%$ powdered milk (Carl Roth, Karlsruhe, Germany) in TBS-T, the membranes were incubated with primary antibodies: GLI1 rabbit pAb \#2553, $\beta$-tubulin (9F3) rabbit mAb \#2128 (both at a dilution 1:1,000) (Cell Signaling Technology, Leiden, Netherlands) with gentle shaking overnight at $4^{\circ} \mathrm{C}$ according to the manufacturer's protocols. Membranes were washed three times with TBS-T. Secondary antibody (horseradish peroxidase-conjugated anti-rabbit pAb, dilution 1:10,000, Jackson Immuno Research, West Grove, PA, USA) was added for $2 \mathrm{~h}$, and the membranes were washed another three times with TBS-T. Proteins were detected using ECL Western Blotting Substrate (Thermo Fisher Scientific, Inc.) with membranes exposed to Amersham Hyperfilm ECL (GE Healthcare, Pittsburgh, PA, USA). A pre-stained protein ladder (PageRuler Plus; Thermo Fisher Scientific, Inc.) was used for determination of molecular weights. ImageJ Software version 1.51s (National Institutes of Health, Bethesda, MD, USA) was utilized for western blot quantification.

ELISA. A673 $\left(0.5 \times 10^{6}\right.$ cells/well $)$, RD-ES $\left(0.5 \times 10^{6}\right.$ cells/well $)$ and TC-71 $\left(0.2 \times 10^{5}\right.$ cells/well $)$ cells were incubated with the drug concentrations indicated for $48 \mathrm{~h}$ in 6 -well plates and the GSK3 beta (Total/Phospho) InstantOne ${ }^{\text {TM }}$ ELISA kit (cat. no. 85-86173-11; Thermo Fisher Scientific, Inc.) was carried out according to the manufacturer's instructions.

Statistical analysis. All statistical tests were performed using GraphPad Prism V8.0 software and statistical differences were analyzed by two-way ANOVA with $\mathrm{P} \leq 0.05, \mathrm{P} \leq 0.01$ and $\mathrm{P} \leq 0.001$ considered as indicative of statistical significance. Multiple comparisons between groups were performed using Tukey's test.

\section{Results}

GLI1 protein expression in ES cell lines. GLI1 protein expression in A673, RD-ES and SK-N-MC cells in comparison to MSC was analyzed in a previous publication (5). For a better comparison of GLI1 protein expression in TC-71 cells, western blotting was repeated including the previously analysed ES cell lines and MSC isolated from a different patient (Fig. 1A and B). All GLI1 splice variants with molecular masses between 100 and $160 \mathrm{kDa}$ (39) were quantified and normalized to tubulin expression. The graph shows the full length GLI1 protein expression relative to MSC (Fig. 1B). As previously shown (5), GLI1 protein abundance was reduced in the A673, RD-ES and SK-N-MC cells when compared to MSC, whereas TC-71 cells showed an increased GLI1 protein expression. Compared to the MSC used in (5), the GLI1 protein expression difference was more pronounced in the actual experiments.

Viability reduction by ATO and etoposide in TC-71 cells. MTS viability assays were performed to determine the $\mathrm{IC}_{50}$ values of ATO and Eto in the TC-71 cell line (Table I). The $\mathrm{IC}_{50}$ value 

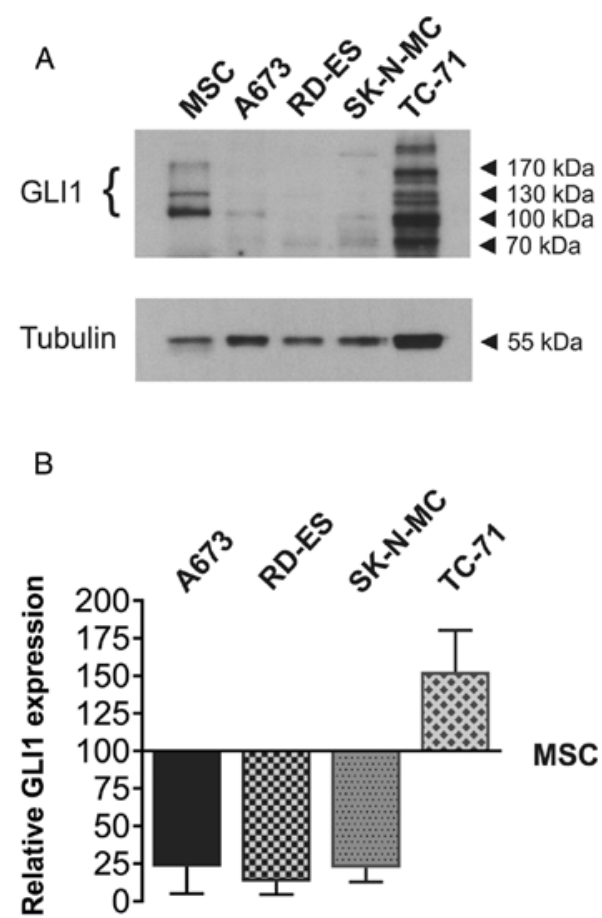

Figure 1. GLI1 protein expression in human ES cell lines. Protein was extracted from ES cell lines (A673, RD-ES, SK-N-MC, TC-71) and MSC. Western blot analysis was performed for GLI1 with tubulin as a loading control. (A) A representative western blot is shown. (B) Signals of three independent experiments were quantified. The graph shows the mean values and standard deviations of GLI1 full length protein expression in ES cell lines compared to MSC. ES, Ewing sarcoma; GLI1, glioma associated oncogene family 1; MSC, mesenchymal stem cells.

for ATO was $2.12 \mu \mathrm{M}$, whereas the half maximal inhibitory concentration of Eto was determined as $0.3 \mu \mathrm{M}$, which was comparable to the drug sensitivity of the other ES cell lines (5).

Influence of the temporal order of repeated drug treatment on caspase activation in ES cell lines. To determine the effect of ATO, Eto and combinations of both drugs on caspase-dependent apoptosis a caspase-3/7 activity assay was performed (Fig. 2A-C). A673, RD-ES and TC-71 cells were either incubated for $96 \mathrm{~h}$ without medium change (MC) or fresh drug solution was added after 48 or $72 \mathrm{~h}$, respectively. Drug doses applied were set individually per cell line as low as possible depending on previous dose finding tests and $\mathrm{IC}_{50}$ values. The ATO doses applied to the A673, RD-ES and TC-71 cells led to a maximal 2-fold increase in caspase-3/7 activation with only slight differences between the treatment sequences (Fig. 2A-C). The general ability of ATO to induce caspase-3 cleavage was previously shown in A673 and SK-N-MC cells applying higher doses, whereas $5 \mu \mathrm{M}$ also ATO induced only minor caspase-3 cleavage in RD-ES cells (5). Compared to ATO, the Eto doses applied in the actual experiments induced more pronounced relative caspase-3/7 activation, which was also influenced by treatment chronology. In A673 cells (Fig. 2A), fresh drug application after 48 or $72 \mathrm{~h}$ was both favorable compared to a single Eto treatment $(\mathrm{P} \leq 0.001)$. In contrast, in RD-ES cells (Fig. 2B) caspase activation could not be further enhanced by fresh drug application after $48 \mathrm{~h}$, whereas a medium change providing fresh Eto after
Table I. ATO and Eto sensitivity of the TC-71 cell line.

\begin{tabular}{lcc}
\hline Inhibitor & Cell line & $\mathrm{IC}_{50}(\mu \mathrm{M})$ \\
\hline ATO & TC-71 & 2.12 \\
Eto & TC-71 & 0.3 \\
\hline
\end{tabular}

MTS assays were performed $96 \mathrm{~h}$ after treatment of TC-71 cells with ATO or Eto. Each drug dose was applied in quadruplicate. Mock treated control was set to $100 \%$ viability. $\mathrm{IC}_{50}$ values were determined by nonlinear regression of MTS results using GraphPad Prism 8. $\mathrm{IC}_{50}$, half maximal inhibitory concentration; ATO, arsenic trioxide; Eto, etoposide.
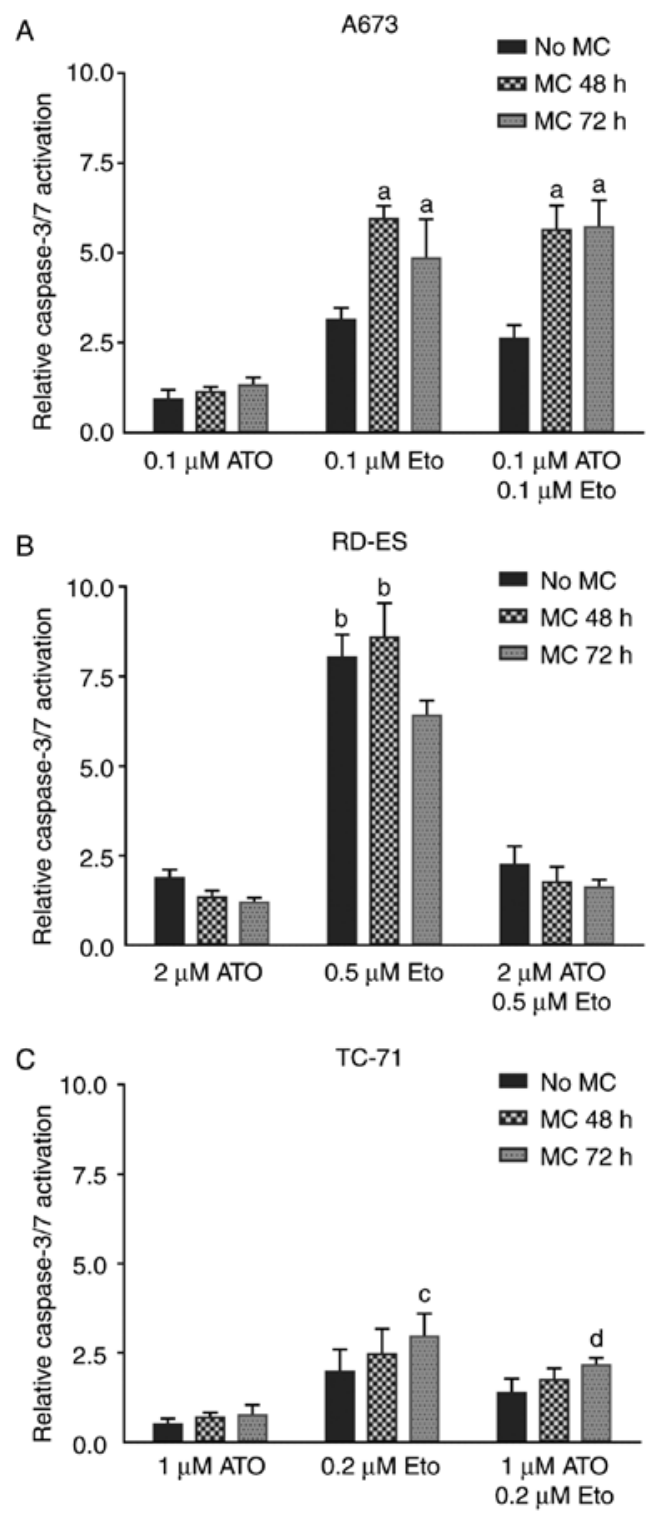

Figure 2. Medium change-dependent caspase activation in human ES cell lines. (A) A673, (B) RD-ES and (C) TC-71 ES cell lines were treated with the ATO and Eto doses indicated. Caspase assays were performed in quadruplicate. Medium was either not changed (no MC) or medium change (MC) adding fresh drug solution was performed after 48 or $72 \mathrm{~h}$. The graph shows the mean values and standard deviations. Caspase activity of mock-treated control was set to 1 . Significant differences are indicated by small letters. ${ }^{\mathrm{a}} \mathrm{P} \leq 0.001$ compared to no MC; ${ }^{\mathrm{b}} \mathrm{P} \leq 0.001$ compared to $\mathrm{MC}$ after $72 \mathrm{~h} ;{ }^{\mathrm{c} P} \leq 0.01$ compared to no MC; ${ }^{\mathrm{d}} \mathrm{P} \leq 0.05$ compared to no MC. ES, Ewing sarcoma; ATO, arsenic trioxide; Eto, etoposide. 
$72 \mathrm{~h}$ significantly reduced the detected caspase- $3 / 7$ activity ( $\mathrm{P} \leq 0.001)$. In TC-71 cells (Fig. 2C), a second Eto application induced higher caspase activity, which was significant for the medium change after $72 \mathrm{~h}$ compared to the incubation without medium change $(\mathrm{P} \leq 0.01)$. In A673 cells the combined application of ATO and Eto resembled the trend of Eto treatment (Fig. 2A) with both the repeated drug application after 48 or $72 \mathrm{~h}$ inducing higher caspase activity compared to the single drug application $(\mathrm{P} \leq 0.001)$. On the contrary, in RD-ES cells (Fig. 2B) the combined application of ATO and Eto in any chronology restricted the caspase activity to a level observed for ATO alone. In TC-71 cells (Fig. 2C), the combined drug application resembled the Eto treatment with a second drug application inducing elevated caspase activity, which was significant for the medium change after $72 \mathrm{~h}$ compared to the incubation without medium change $(\mathrm{P} \leq 0.05)$. To summarize, in the A673 and TC-71 cells caspase activity after the combination treatment was dominated by the Eto effect, whereas in RD-ES cells ATO application suppressed the pro-apoptotic Eto impact.

Influence of pre-treatment chronology on caspase activation in ES cell lines. To further address the interdependence of ATO and Eto effects on caspase activation in the ES cell lines (A673, RD-ES and TC-71) consecutive ATO and Eto treatment was compared to single or combined drug application applying a medium change after 48 or $72 \mathrm{~h}$ (Fig. 3A-C). In A673 cells (Fig. 3A), the treatment with Eto, the combined treatment with ATO and Eto and the pre-treatment with ATO followed by Eto incubation all led to comparable caspase-3/7 activation, regardless of when the medium was changed, which was significantly higher compared to Eto pre-treatment followed by ATO ( $\mathrm{P} \leq 0.001)$. In addition, in the case of pre-Eto incubation in A673 cells, a later medium change applying ATO after $72 \mathrm{~h}$ increased caspase activity compared to the ATO application $48 \mathrm{~h}$ after initial Eto treatment. In RD-ES cells (Fig. 3B), pure Eto incubation and pre-ATO treatment followed by Eto after $48 \mathrm{~h}$, both were significantly more effective compared to the combined treatment and pre-Eto application followed by ATO after $48 \mathrm{~h}$. Remarkably, when the medium was changed after $72 \mathrm{~h}$, pre-Eto treatment followed by ATO showed a similar effect on caspase activation compared to Eto alone, which was both significantly higher compared to the combined treatment and pre-ATO application. Additionally, RD-ES viability as determined by MTS assay (Fig. S1) was significantly less compromised by pre-ATO treatment followed by Eto compared to all other treatments, whereas combined treatment led to the most significant viability reduction. In TC-71 cells (Fig. 3C), the applied doses of ATO and Eto caused no significant differences in caspase activation. Although, similar to A673 cells, the treatment with Eto, the combined treatment with ATO and Eto and the pre-treatment with ATO followed by Eto incubation were all slightly more effective compared to pre-Eto incubation followed by ATO. In summary, a distinct caspase activation was observed after Eto treatment in all 3 ES cell lines examined, whereas individual ATO treatment sequences cell line-specifically suppressed caspase activation by Eto.

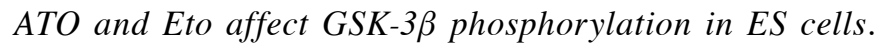
GSK-3 $\beta$ is implicated in various signaling pathways affecting
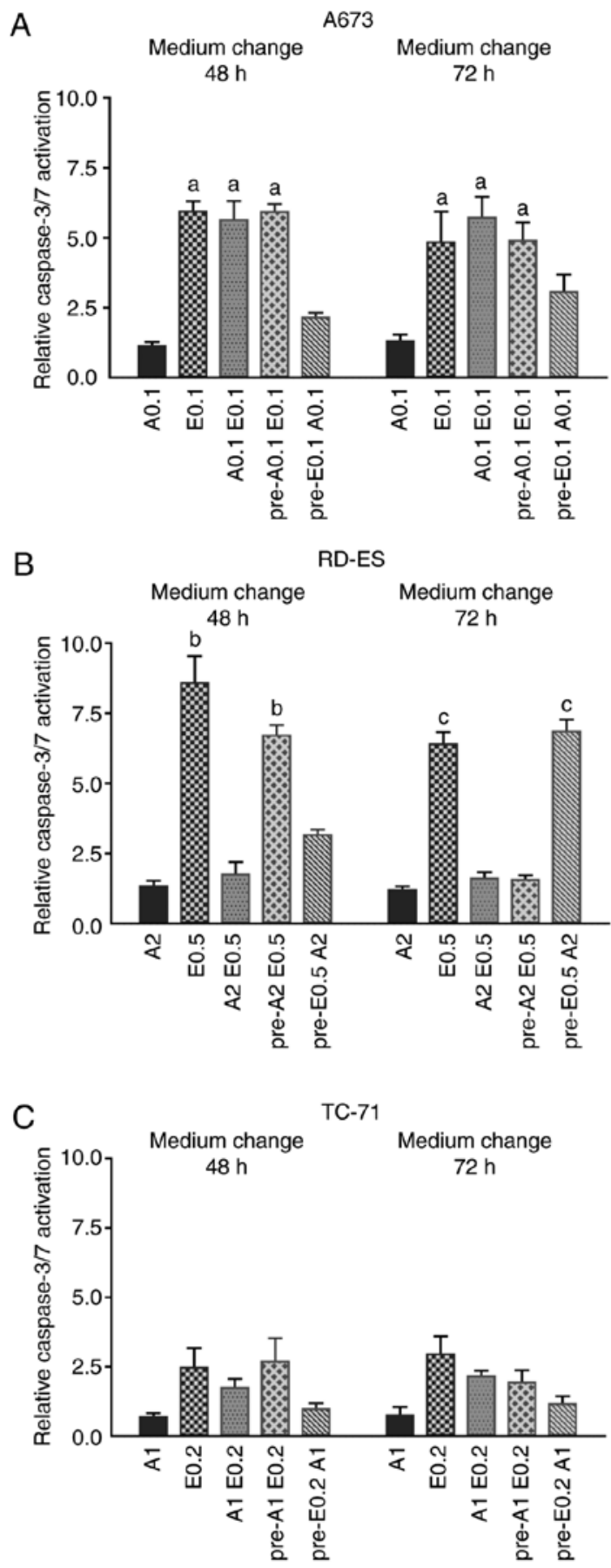

Figure 3. ATO and Eto treatment chronology-dependent caspase activation in human ES cell lines. (A) A673, (B) RD-ES and (C) TC-71 ES cell lines were treated with ATO (A0.1, A1 and A2) and Eto (E0.1, E0.5 and E0.2) at the indicated doses $(\mu \mathrm{M})$. Medium change was performed after 48 or $72 \mathrm{~h}$. In case of pre-treatment, the drug was replaced with the medium change, whereas in all other cases the previous treatment was continued. The graph shows the mean values and standard deviations of four independent experiments. Caspase activity of mock treated control was set to 1 . Significant differences between groups are indicated by small letters. ${ }^{\mathrm{a}} \mathrm{P} \leq 0.001$ compared to pre-E0.1 A0.1; ${ }^{\mathrm{b}} \mathrm{P} \leq 0.001$ compared to A2 E0.5 and pre-E0.5 A2; ${ }^{\mathrm{C}} \mathrm{P} \leq 0.001$ compared to A2 E0.5 and pre-A2 E0.5. ES, Ewing sarcoma; ATO, arsenic trioxide; Eto, etoposide.

metabolism, cell survival and apoptosis (40). Yet, the impact of ATO and Eto on inhibitory GSK-3 $\beta$ serine 9 phosphorylation in ES cells has not been investigated to date. To examine the individual and combined Eto and ATO effects in the ES cell lines 


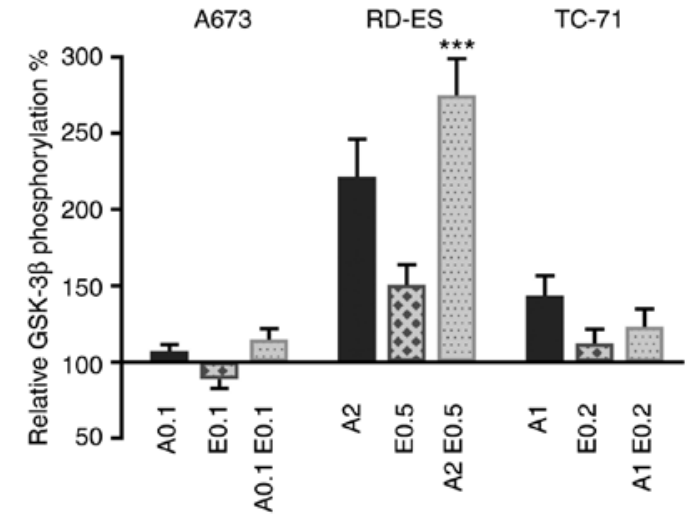

Figure 4. Inhibitory GSK-3 $\beta$ phosphorylation after ATO and Eto treatment of human ES cell lines. ELISA assay was performed with A673, RD-ES and TC-71 cell lines treated with the ATO (A0.1, A1 and A2) and Eto (E0.1, E0.5 and E0.2) doses as indicated $(\mu \mathrm{M})$. Relative GSK-3 $\beta$ phosphorylation was calculated by normalizing GSK-3 $\beta$ phosphorylation to total GSK- $3 \beta$ abundance. The graph shows the mean values and standard deviations of four independent experiments. Mock-treated control was set to $100 \%$ GSK- $3 \beta$ abundance, respectively phosphorylation $\left({ }^{* * *} \mathrm{P} \leq 0.001\right.$ relative to single treatment). GSK3- $\beta$, glycogen synthase kinase-3 $\beta$; ES, Ewing sarcoma; ATO, arsenic trioxide; Eto, etoposide.

(A673, RD-ES and TC-71) both drugs were applied for $48 \mathrm{~h}$, followed by an ELISA assay to determine total GSK-3 $\beta$ and phosphorylated GSK-3 $\beta$ protein levels (Fig. 4). In the A673 cells, the ATO and Eto doses applied barely changed the relative GSK-3 $\beta$ phosphorylation. In contrast, in the RD-ES cells especially the combined application of ATO and Eto increased the relative GSK-3 $\beta$ phosphorylation ( $\mathrm{P} \leq 0.001$ compared to single treatment). ATO alone also considerably induced relative GSK-3 $\beta$ phosphorylation in the RD-ES cells. In the TC-71 cells, ATO slightly increased relative GSK-3 $\beta$ phosphorylation, whereas the combination treatment had less impact. This indicates that the applied ATO drug doses specifically affect the inhibitory GSK-3 $\beta$ phosphorylation in RD-ES cells, where the pronounced GSK-3 $\beta$ phosphorylation after combination treatment coincides with restricted caspase activity.

Inherent and ATO-dependent multidrug transporter gene expression in ES cells. MRP1 and MDR1 expression have been previously shown in ES samples and cell lines $(9,10)$. Both multidrug transporters are implicated in acquired Eto resistance of various cancer cells (41). To provide an impression of relative MRP1 and MDR1 mRNA abundance, qRT-PCR was performed in the ES cell lines (A673, RD-ES and TC-71) compared to the MSC (Fig. 5A and C). In addition, the ATO impact on MRP1 and MDR1 mRNA expression in ES cell lines and MSC was examined (Fig. 5B and D). Indeed, MRP1 mRNA expression was abundant in MSC, whereas all ES cell lines showed a distinct, yet, compared to MSC. reduced MRP1 mRNA expression (Fig. 5A). After $96 \mathrm{~h}$ treatment with $5 \mu \mathrm{M}$ ATO, the MRP1 mRNA expression increased approximately 6-fold in the MSC. In addition, the RD-ES cells showed an enhanced MRP1 mRNA expression, whereas ATO reduced MRP1 mRNA abundance in the A673 and TC-71 cells, actually increasing the expression differences between MSC and the two ES cell lines. In contrast, basic MDR1 mRNA expression was more pronounced in the ES cell lines compared to
MSC, where MDR1 expression was at the detection limit of the qRT-PCR. In particular, A673 cells showed robust MDR1 expression, which was still enhanced by ATO treatment. Moreover in the TC-71 cells, ATO increased MDR1 expression, whereas MDR1 remained nearly unchanged in the MSC and RD-ES cells. Therefore, ES cell lines exhibit an obvious surplus of MDR1 mRNA compared to MSC, which was still enhanced by ATO in the A673 and TC-71 cells.

\section{Discussion}

ES are characterized by a poor differentiation status with mesenchymal progenitor cell features (42), limited cell adhesion (43) and a heterogeneous EWS-FLI1 protein expression promoting phenotypic diversity (4). These features contribute to aggressiveness, early metastasis and acquired treatment resistance of ES $(1,8)$ necessitating new treatment strategies which consider the specific nature of ES.

As previously shown, the single and combined application of ATO and Eto are capable of impairing metabolic activity, as assessed by MTS viability assay, and to induce significant cell death, as determined by eFluor 450 incorporation, in the ES cell lines A673, RD-ES and SK-N-MC, which was clearly increased after combined treatment compared to individual treatment in the RD-ES and SK-N-MC cells. In addition, western blot analysis indicated induction of poly(ADP-ribose) polymerase 1 (PARP1) and caspase 3 cleavage upon Eto treatment of A673, RD-ES and SK-N-MC cells. Notably, apoptosis induction by ATO, manifested as caspase-3 and PARP1 cleavage, was only observed in A673 and SK-N-MC cells, indicating the existence of additional caspase-3-independent cell death mechanisms at least in RD-ES cells (5). Indeed, ATO has been shown to activate several cell death pathways in human tumor cells including ROS-induced PARP1-dependent or caspase-3-dependent mitochondrial apoptosis but also necrosis $(21,28,44,45)$. In contrast, Eto mainly induced caspase-3-dependent apoptotic cell death in ES cells $(5,12)$.

In the present study, the ATO and Eto doses applied on RD-ES cells were consistent with previously published doses. In A673 cells, the ATO dose was maintained whereas Eto was reduced to one-tenth of the previous dose which was still efficient to induce caspase activation (5). Using low dose ATO and Eto, the intensity of caspase-3/7 activation was mainly determined by the Eto doses in A673 and TC-71 cells, whereas in RD-ES cells ATO application actively suppressed Eto-induced apoptosis dependent on the treatment chronology. Notably, in RD-ES cells a late medium change applying ATO after $72 \mathrm{~h}$ of Eto incubation could no more suspend apoptosis induction, whereas a 48-h Eto incubation followed by $48 \mathrm{~h}$ ATO largely suppressed apoptosis. On the other hand, a 48-h ATO pre-incubation was not able to suppress subsequent Eto-dependent apoptosis, whereas only $24 \mathrm{~h}$ Eto application after a 72-h ATO pre-incubation was not sufficient to obtain a high caspase activation rate. Considering viability reduction in RD-ES cells, a strong decline could be observed upon combined treatment, which is consistent with previous results (5). Yet, ATO pre-incubation largely prevented viability reduction by Eto. In the experiments, the applied ATO and Eto doses were set individually dependent on previous dose finding tests and 
A

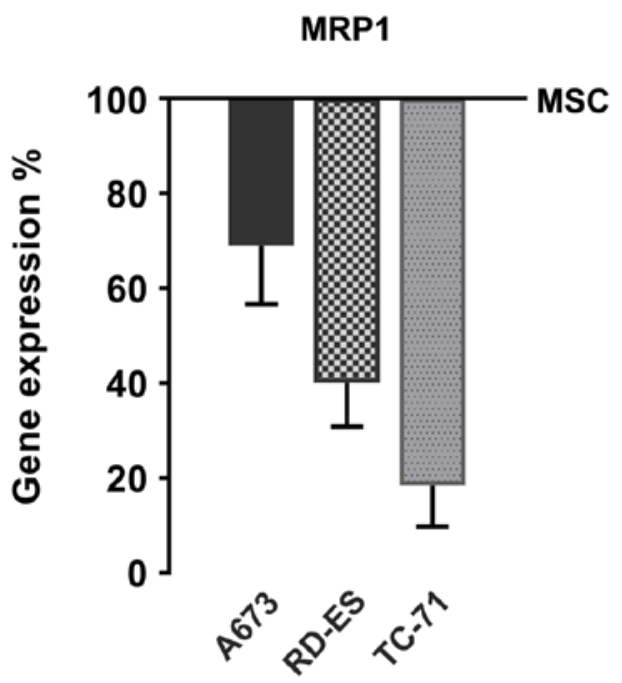

C

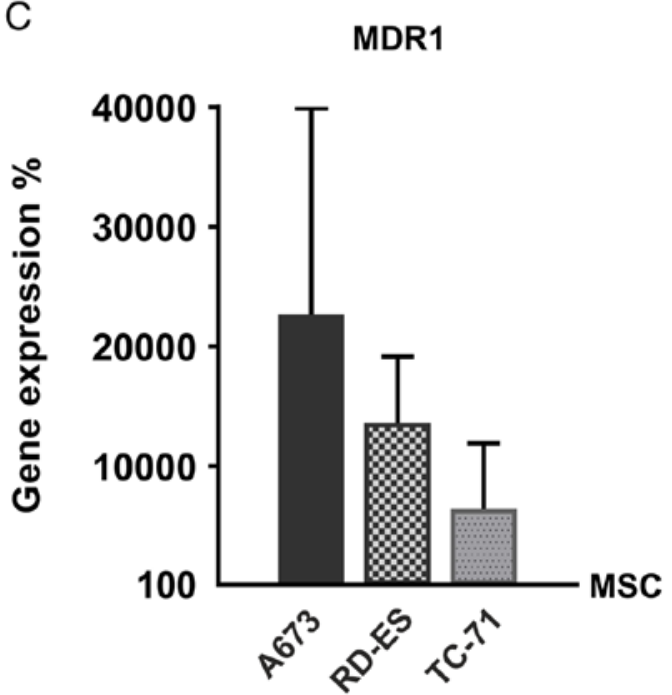

B

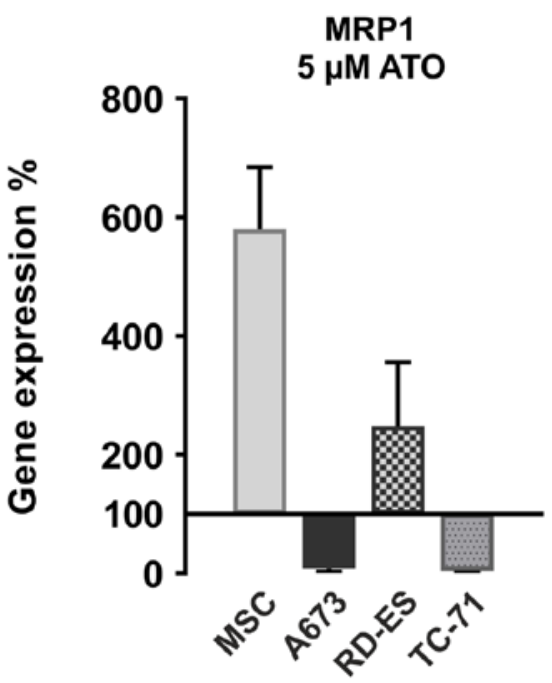

D

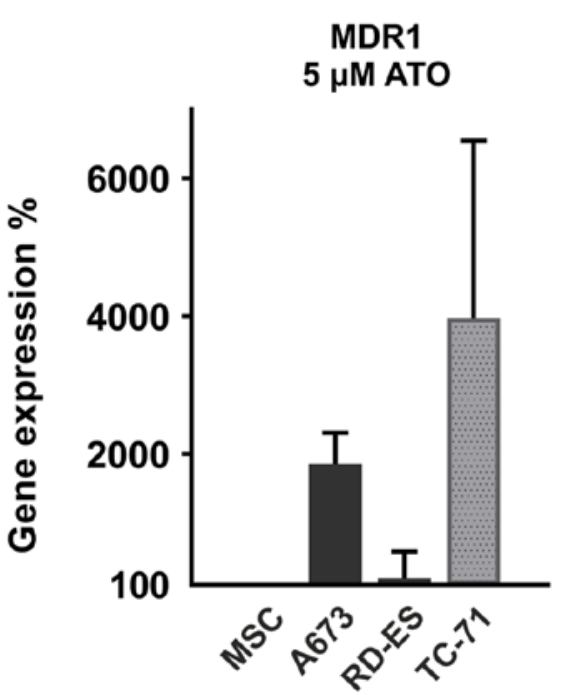

Figure 5. Basic and ATO-dependent MRP1 and MDR1 expression. Total RNA was extracted from MSC as well as A673, RD-ES and TC-71 ES cell lines. Quantitative RT-PCR was performed for the genes MRP1 and MDR1 in quadruplicate and normalized to the housekeeping gene TBP. (A and C) Expression levels relative to MSC are shown. (B and D) Expression levels after treatment with $5 \mu \mathrm{M}$ ATO relative to basic expression are shown. ATO, arsenic trioxide; MDR1, multidrug resistance protein 1; MRP1, multidrug resistance-associated protein 1; MSC, mesenchymal stem cells.

$\mathrm{IC}_{50}$ values. Since A673 cells exhibited the highest sensitivity, the low ATO dose applied may not interfere with Eto-dependent apoptosis to the same extent as observed in the other cell lines. TC-71 cells, although being highly Eto sensitive in viability assays, showed only comparably low caspase activation rates upon Eto treatment with a tendency of apoptosis reduction by concomitant or subsequent ATO treatment. Based on previous and actual observations, augmented cell death of RD-ES cells ascertained upon combination treatment with both drugs (5) must be triggered by a caspase-3/7-independent pathway since caspase activation is impaired by concomitant ATO treatment. Taking the example of these three individual ES cell lines a remarkable heterogeneity of ES response to ATO and Eto treatment becomes apparent, complicating the prediction of treatment success.

Indeed, ATO affects various signaling pathways with low doses up to $0.5 \mu \mathrm{M}$ actually inducing differentiation in APL cells (18), whereas higher doses up to $5 \mu \mathrm{M}$ commonly induce cell death $(5,19,21,28,44,45)$. ATO directly acts on the Hh pathway by binding and inhibiting GLI transcription factors (46). Yet, of all the ES cell lines tested, only TC-71 cells showed a marked GLI1 protein expression, which was increased compared to the MSC. However, this did not coincide with an enhanced caspase-3/7 activation by ATO treatment, excluding inhibition of GLI1-dependent transcription as a crucial trigger for caspase-dependent apoptosis induction in ES cells. Since GSK-3 $\beta$ serine 9 phosphorylation interferes with apoptosis induction in different cancer cell lines (32), physiological ATO and Eto doses were tested in ES cells concerning their impact on inhibitory GSK-3 $\beta$ serine 9 phosphorylation. Actually, ATO and especially the combination of Eto and ATO largely induced inhibitory GSK-3 $\beta$ phosphorylation in RD-ES cells, coinciding with suppression of apoptosis in this cell line, whereas GSK-3 $\beta$ phosphorylation in A673 and TC-71 cells was only marginally affected by the ATO and Eto doses applied. Therefore, the mechanism of apoptosis suppression in RD-ES 
cells may depend on ATO-mediated GSK-3 $\beta$ inhibition and subsequent suppression of mitochondrial apoptosis (47).

Multidrug resistance is common in recurrent and metastatic ES $(8,11)$. MRP1 protein expression has been shown in A673, RD-ES and SK-N-MC cells (10). Both, MRP1 and MDR1 can actively exclude Eto from human cells (41). In addition, MRP1 and potentially also MDR1 transport arsenic out of human cells $(48,49)$. Interestingly, ATO itself has been shown to induce multidrug resistance via upregulation of MRP1 expression (50), while it suppresses GLI1-dependent MRP1 and MDR1 transcription (51). Multidrug transporter expression by MSC is an established feature (52), which may contribute to observed drug tolerance (5). To elucidate the basal and ATO-dependent MRP1 and MDR1 expression in A673, RD-ES and TC-71 cells compared to MSC, qRT-PCR was performed, showing that MSC indeed express higher MRP1 mRNA levels compared to the ES cell lines A673, RD-ES and TC-71, while MDR1 mRNA expression was clearly more abundant in the ES cell lines. ATO treatment had a diverse effect on MRP1 and MDR1 expression. While MRP1 mRNA expression increased upon ATO incubation in MSC and RD-ES, it was attenuated in A673 and TC-71 cells. Yet, MDR1 mRNA expression was enhanced by ATO in A673 and TC-71 cells. To summarize, ATO reinforces the differences of MRP1 and MDR1 mRNA expression in MSC compared to A673 and TC-71 ES cells. Nevertheless, further experiments are needed to clarify the impact of ATO as well as Eto and ATO combination treatment on MRP1 and MDR1 protein expression and activity in ES cell lines to determine a possible interference with drug resistance.

New therapeutic approaches for ES targeting receptor tyrosine kinases, the EWS-FLI1 fusion protein and immunotherapies using $\mathrm{T}$ cells and NK cells are currently being evaluated in clinical trials (53). Yet, usually only a small subset of patients responds to the individual therapies underlining the intricate heterogeneity of ES (54). Combining ATO and Eto remains a promising approach for cell death induction in ES, although individual ES characteristics potentially impairing the efficacy must be considered.

\section{Acknowledgements}

Not applicable.

\section{Funding}

No funding was received.

\section{Availability of data and materials}

All data generated or analyzed during this study are included in this published article.

\section{Authors' contributions}

JEL and RR carried out the experiments. JEL, RR, KAB, SBS, RH and FT collected and analyzed the data. KAB and FT designed the experiments. KAB and JEL wrote, improved and finalized the manuscript. All authors read and approved the final manuscript and agree to be accountable for all aspects of the research in ensuring that the accuracy or integrity of any part of the work are appropriately investigated and resolved.

\section{Ethics approval and consent to participate}

Ethics approval was provided by The Ethics Committee of the Medical Faculty of the University Hospital Tuebingen, project no. 401/2013 BO2. Bone marrow-derived MSC were isolated at the University Hospital Tuebingen after written informed consent of the patients.

\section{Patient consent for publication}

Not applicable.

\section{Authors' information}

Julia E. Lenz, ORCID 0000-0001-5890-3489. Frank Traub, ORCID 0000-0002-6400-3257.

\section{Competing interests}

The authors declare that they have no competing interests.

\section{References}

1. Ross KA, Smyth NA, Murawski CD and Kennedy JG: The biology of Ewing sarcoma. ISRN Oncol 2013: 759725, 2013.

2. Tirode F, Laud-Duval K, Prieur A, Delorme B, Charbord P and Delattre O: Mesenchymal stem cell features of Ewing tumors. Cancer Cell 11: 421-429, 2007.

3. Beauchamp E, Bulut G, Abaan O, Chen K, Merchant A, Matsui W, Endo Y, Rubin JS, Toretsky J and Uren A: GLI1 is a direct transcriptional target of EWS-FLI1 oncoprotein. J Biol Chem 284: 9074-9082, 2009.

4. Franzetti GA, Laud-Duval K, van der Ent W, Brisac A, Irondelle M, Aubert S, Dirksen U, Bouvier C, de Pinieux G, Snaar-Jagalska E, et al: Cell-to-cell heterogeneity of EWSR1-FLI1 activity determines proliferation/migration choices in Ewing sarcoma cells. Oncogene 36: 3505-3514, 2017.

5. Boehme KA, Nitsch J, Riester R, Handgretinger R, Schleicher SB, Kluba T and Traub F: Arsenic trioxide potentiates the effectiveness of etoposide in Ewing sarcomas. Int J Oncol 49: 2135-2146, 2016.

6. Beauchamp EM, Ringer L, Bulut G, Sajwan KP, Hall MD, Lee YC, Peaceman D, Ozdemirli M, Rodriguez O, Macdonald TJ, et al: Arsenic trioxide inhibits human cancer cell growth and tumor development in mice by blocking hedgehog/GLI pathway. J Clin Invest 121: 148-160, 2011.

7. Sand LG, Szuhai K and Hogendoorn PC: Sequencing overview of Ewing sarcoma: A journey across genomic, epigenomic and transcriptomic landscapes. Int J Mol Sci 16: 16176-16215, 2015.

8. May WA, Grigoryan RS, Keshelava N, Cabral DJ, Christensen LL, Jenabi J, Ji L, Triche TJ, Lawlor ER and Reynolds CP: Characterization and drug resistance patterns of Ewing's sarcoma family tumor cell lines. PLoS One 8: e80060, 2013.

9. Oda Y, Dockhorn-Dworniczak B, Jürgens H and Roessner A: Expression of multidrug resistance-associated protein gene in Ewing's sarcoma and malignant peripheral neuroectodermal tumor of bone. J Cancer Res Clin Oncol 123: 237-239, 1997.

10. Roundhill EA and Burchill SA: Detection and characterisation of multi-drug resistance protein 1 (MRP-1) in human mitochondria. Br J Cancer 106: 1224-1233, 2012.

11. Roessner A, Ueda Y, Bockhorn-Dworniczak B, Blasius S, Peters A, Wuisman P, Ritter J, Paulussen M, Jürgens $H$ and Böcker W: Prognostic implication of immunodetection of $\mathrm{P}$ glycoprotein in Ewing's sarcoma. J Cancer Res Clin Oncol 119: 185-189, 1993.

12. Mauz-Körholz C, Kachel M, Harms-Schirra B, Klein-Vehne A, Tunn PU and Körholz D: Drug-induced caspase-3 activation in a Ewing tumor cell line and primary Ewing tumor cells. Anticancer Res 24: 145-149, 2004. 
13. Casali PG, Bielack S, Abecassis N, Aro HT, Bauer S, Biagini R, Bonvalot S, Boukovinas I, Bovee JVMG, Brennan B, et al: ESMO Guidelines Committee, paedcan and ERN EURACAN: Bone sarcomas: ESMO-PaedCan-EURACAN clinical practice guidelines for diagnosis, treatment and follow-up. Ann Oncol 29 (Suppl 4): iv79-iv95, 2018.

14. Clifford B, Beljin M, Stark GR and Taylor WR: G2 arrest in response to topoisomerase II inhibitors: The role of p53. Cancer Res 63: 4074-4081, 2003.

15. Lin CF, Tsai CC, Huang WC, Wang YC, Tseng PC, Tsai TT and Chen CL: Glycogen synthase kinase- $3 \beta$ and caspase- 2 mediate ceramide- and etoposide-induced apoptosis by regulating the lysosomal-mitochondrial axis. PLoS One 11: e0145460, 2016.

16. Lee KI, Su CC, Yang CY, Hung DZ, Lin CT, Lu TH, Liu SH and Huang CF: Etoposide induces pancreatic $\beta$-cells cytotoxicity via the JNK/ERK/GSK-3 signaling-mediated mitochondria-dependent apoptosis pathway. Toxicol In Vitro 36: 142-152, 2016.

17. Ngok-Ngam P, Watcharasit P, Thiantanawat A and Satayavivad J: Pharmacological inhibition of GSK3 attenuates DNA damage-induced apoptosis via reduction of p53 mitochondrial translocation and Bax oligomerization in neuroblastoma SH-SY5Y cells. Cell Mol Biol Lett 18: 58-74, 2013.

18. Lengfelder E, Hofmann WK and Nowak D: Impact of arsenic trioxide in the treatment of acute promyelocytic leukemia. Leukemia 26: 433-442, 2012

19. Boehme KA, Zaborski JJ, Riester R, Schweiss SK, Hopp U, Traub F, Kluba T, Handgretinger R and Schleicher SB: Targeting hedgehog signalling by arsenic trioxide reduces cell growth and induces apoptosis in rhabdomyosarcoma. Int $\mathrm{J}$ Oncol 48 : 801-812, 2016.

20. Au WY, Tam S, Fong BM and Kwong YL: Determinants of cerebrospinal fluid arsenic concentration in patients with acute promyelocytic leukemia on oral arsenic trioxide therapy. Blood 112: 3587-3590, 2008

21. Kang YH, Yi MJ, Kim MJ, Park MT, Bae S, Kang CM, Cho CK Park IC, Park MJ, Rhee CH, et al: Caspase-independent cell death by arsenic trioxide in human cervical cancer cells: Reactive oxygen species-mediated poly(ADP-ribose) polymerase-1 activation signals apoptosis-inducing factor release from mitochondria. Cancer Res 64: 8960-8967, 2004.

22. Beauchamp EM and Uren A: A new era for an ancient drug: Arsenic trioxide and Hedgehog signaling. Vitam Horm 88 333-354, 2012

23. Dawood M, Hamdoun S and Efferth T: Multifactorial modes of action of arsenic trioxide in cancer cells as analyzed by classical and network pharmacology. Front Pharmacol 9: 143, 2018.

24. Chiu HW, Tseng YC, Hsu YH, Lin YF, Foo NP, Guo HR and Wang YJ: Arsenic trioxide induces programmed cell death through stimulation of ER stress and inhibition of the ubiquitin-proteasome system in human sarcoma cells. Cancer Lett 356: 762-772, 2015

25. Kozono S, Lin YM, Seo HS, Pinch B, Lian X, Qiu C, Herbert MK, Chen CH, Tan L, Gao ZJ, et al: Arsenic targets Pin1 and cooperates with retinoic acid to inhibit cancer-driving pathways and tumor-initiating cells. Nat Commun 9: 3069, 2018

26. Jiang L, Wang L, Chen L, Cai GH, Ren QY, Chen JZ, Shi HJ and $\mathrm{Xie} \mathrm{YH}$ : As2O3 induces apoptosis in human hepatocellular carcinoma HepG2 cells through a ROS-mediated mitochondrial pathway and activation of caspases. Int J Clin Exp Med 8: 2190-2196, 2015.

27. Yen YP, Tsai KS, Chen YW, Huang CF, Yang RS and Liu SH: Arsenic induces apoptosis in myoblasts through a reactive oxygen species-induced endoplasmic reticulum stress and mitochondrial dysfunction pathway. Arch Toxicol 86: 923-933, 2012

28. Kumar S, Yedjou CG and Tchounwou PB: Arsenic trioxide induces oxidative stress, DNA damage, and mitochondrial pathway of apoptosis in human leukemia (HL-60) cells. J Exp Clin Cancer Res 33: 42, 2014.

29. States JC: Disruption of mitotic progression by arsenic. Biol Trace Elem Res 166: 34-40, 2015

30. Huang HS, Liu ZM and Cheng YL: Involvement of glycogen synthase kinase-3 $\beta$ in arsenic trioxide-induced p21 expression. Toxicol Sci 121: 101-109, 2011

31. Schleicher SB, Zaborski JJ, Riester R, Zenkner N, Handgretinger R, Kluba T, Traub F and Boehme KA: Combined application of arsenic trioxide and lithium chloride augments viability reduction and apoptosis induction in human rhabdomyosarcoma cell lines. PLoS One 12: e0178857, 2017.

32. Beurel E and Jope RS: The paradoxical pro- and anti-apoptotic actions of GSK3 in the intrinsic and extrinsic apoptosis signaling pathways. Prog Neurobiol 79: 173-189, 2006.
33. Battula VL, Treml S, Bareiss PM, Gieseke F, Roelofs H, de Zwart P, Müller I, Schewe B, Skutella T, Fibbe WE, et al: Isolation of functionally distinct mesenchymal stem cell subsets using antibodies against CD56, CD271, and mesenchymal stem cell antigen-1. Haematologica 94: 173-184, 2009.

34. Livak KJ and Schmittgen TD: Analysis of relative gene expression data using real-time quantitative PCR and the 2(-Delta Delta C(T)) method. Methods 25: 402-408, 2001

35. Laurendeau I, Ferrer M, Garrido D, D'Haene N, Ciavarelli P, Basso A, Vidaud M, Bieche I, Salmon I and Szijan I: Gene expression profiling of the hedgehog signaling pathway in human meningiomas. Mol Med 16: 262-270, 2010.

36. Xie J, Li DW, Chen XW, Wang F and Dong P: Expression and significance of hypoxia-inducible factor- $1 \alpha$ and MDR1/Pglycoprotein in laryngeal carcinoma tissue and hypoxic Hep-2 cells. Oncol Lett 6: 232-238, 2013.

37. König J, Hartel M, Nies AT, Martignoni ME, Guo J, Büchler MW, Friess $\mathrm{H}$ and Keppler D: Expression and localization of human multidrug resistance protein (ABCC) family members in pancreatic carcinoma. Int J Cancer 115: 359-367, 2005.

38. Benaitreau D, Dieudonné MN, Dos Santos E, Leneveu MC, Mazancourt PD and Pecquery R: Antiproliferative effects of adiponectin on human trophoblastic cell lines JEG-3 and BeWo. Biol Reprod 80: 1107-1114, 2009.

39. Amable L, Gavin E, Kudo K, Meng E, Rocconi RP, Shevde LA and Reed E: GLI1 upregulates C-JUN through a specific 130-kDa isoform. Int J Oncol 44: 655-661, 2014.

40. McCubrey JA, Steelman LS, Bertrand FE, Davis NM, Sokolosky M, Abrams SL, Montalto G, D'Assoro AB, Libra M, Nicoletti F, et al: GSK-3 as potential target for therapeutic intervention in cancer. Oncotarget 5: 2881-2911, 2014.

41. Gottesman MM: Mechanisms of cancer drug resistance. Annu Rev Med 53: 615-627, 2002

42. Kauer M, Ban J, Kofler R, Walker B, Davis S, Meltzer P and Kovar H: A molecular function map of Ewing's sarcoma. PLoS One 4: e5415, 2009

43. Chaturvedi A, Hoffman LM, Jensen CC, Lin YC, Grossmann AH, Randall RL, Lessnick SL, Welm AL and Beckerle MC: Molecular dissection of the mechanism by which EWS/FLI expression compromises actin cytoskeletal integrity and cell adhesion in Ewing sarcoma. Mol Biol Cell 25: 2695-2709, 2014.

44. McCafferty-Grad J, Bahlis NJ, Krett N, Aguilar TM, Reis I, Lee KP and Boise LH: Arsenic trioxide uses caspase-dependent and caspase-independent death pathways in myeloma cells. Mol Cancer Ther 2: 1155-1164, 2003.

45. Scholz C, Wieder T, Stärck L, Essmann F, Schulze-Osthoff K, Dörken B and Daniel PT: Arsenic trioxide triggers a regulated form of caspase-independent necrotic cell death via the mitochondrial death pathway. Oncogene 24: 1904-1913, 2005.

46. Raju GP: Arsenic: A potentially useful poison for hedgehog-driven cancers. J Clin Invest 121: 14-16, 2011

47. Yang K, Chen Z, Gao J, Shi W, Li L, Jiang S, Hu H, Liu Z, Xu D and $\mathrm{Wu} \mathrm{L}$ : The Key roles of GSK-3 $\beta$ in regulating mitochondrial activity. Cell Physiol Biochem 44: 1445-1459, 2017.

48. Shukalek CB, Swanlund DP, Rousseau RK, Weigl KE, Marensi V, Cole SP and Leslie EM: Arsenic triglutathione [As(GS)3] transport by multidrug resistance protein 1 (MRP1/ABCC1) is selectively modified by phosphorylation of Tyr920/Ser921 and glycosylation of Asn19/Asn23. Mol Pharmacol 90: 127-139, 2016.

49. Maciaszczyk-Dziubinska E, Wawrzycka D and Wysocki R: Arsenic and antimony transporters in eukaryotes. Int $\mathbf{J}$ Mol Sci 13: 3527-3548, 2012

50. Seo T, Urasaki Y and Ueda T: Establishment of an arsenic trioxide-resistant human leukemia cell line that shows multidrug resistance. Int J Hematol 85: 26-31, 2007.

51. Santisteban M: ABC transporters as molecular effectors of pancreatic oncogenic pathways: The Hedgehog-GLI model. J Gastrointest Cancer 41: 153-158, 2010

52. Erdei Z, Lőrincz R, Szebényi K, Péntek A, Varga N, Likó I, Várady G, Szakács G, Orbán TI, Sarkadi B and Apáti A: Expression pattern of the human ABC transporters in pluripotent embryonic stem cells and in their derivatives. Cytometry B Clin Cytom 86: 299-310, 2014

53. Brown HK, Schiavone K, Gouin F, Heymann MF and Heymann D: Biology of bone sarcomas and new therapeutic developments. Calcif Tissue Int 102: 174-195, 2018.

54. Yu H, Ge Y, Guo L and Huang L: Potential approaches to the treatment of Ewing's sarcoma. Oncotarget 8: 5523-5539, 2017. 